\title{
The Use of Binary Online Lessons in the Context of Forming Critical Thinking in Future Journalists
}

\author{
Nataliya Poplavska ${ }^{1,}$, , Halyna Synorub ${ }^{1}$, Hanna Yordan ${ }^{1}$, Olesia Medynska ${ }^{1}$, Oksana Kushnir $^{1} \&$ Nataliya \\ Dragan-Ivanets ${ }^{1}$ \\ ${ }^{1}$ Department of Journalism, Ternopil Volodymyr Hnatiuk National Pedagogical University, Ternopil, Ukraine \\ *Correspondence: Department of Journalism, Ternopil Volodymyr Hnatiuk National Pedagogical University, 2, \\ Kryvonosa, Ternopil, 46000, Ukraine
}

Received: December 9, 2021

Accepted: January 6, 2022 Online Published: January 17, 2022

doi:10.5430/jct.v11n1p273

URL: https://doi.org/10.5430/jct.v11n1p273

\begin{abstract}
The emphasis is placed on changes in the educational field of Ukraine and the importance of forming the competencies of future journalists. Features of the application of modern information technologies in distance learning are outlined. A review of scientific sources of Ukrainian and foreign scientists on the stated issues. The relevance of the introduction of integrated technologies in modern journalism education, which contributes to improving the training of future professionals, the formation of his competencies. Definitions of the concepts "integrated learning", "interdisciplinary approach", "team learning" are defined. The focus is on the need to use an integrated approach - binary classes to increase the level of cognitive activity and activity of higher education. The focus is on forming multi-qualification of the modern journalist working in convergent newsrooms. Means of practical training of students that significantly affect the formation of professional competencies are identified. The importance of media literacy and critical thinking for the training of future journalists has been updated. According to the results of an online survey of students, it was found that interactive teaching methods increase the level of critical thinking and form skills of verification of information as a program competence of future media professionals. Scientific approaches to understanding the concept of "binary class", the organization and methods of its implementation, the features of distance learning during the pandemic. The binary online lesson "Critical Thinking: Verification of Online Content" for students-journalists in the disciplines of journalism (photo and online journalism) on the Zoom platform is described. The skills and abilities necessary for the future mediator, which create a positive professional image and public authority, are generalized and classified. Summarized the application of new learning technologies for self-realization of students, the atmosphere of cooperation, increased responsibility of teachers for the results of their work. Vectors of further research of integrated interdisciplinary classes in the educational process are outlined.
\end{abstract}

Keywords: information, media content, media, journalism education, media literacy, integrated technologies, binary lessons, distance learning.

\section{Introduction}

The humanization and democratization of Ukrainian society, the rapid development of the information space have led to significant changes in education. In particular, new approaches have emerged on ways to develop the general and professional competencies of higher education seekers. The new reality of modern education - distance learning caused by the COVID-19 pandemic - also requires radical changes (Slamet et. al., 2021). To ensure the full functioning of the educational process in quarantine, there is a need to improve the methods and principles of distance learning, whose objectives are to create comfortable conditions for students and teachers, improve pedagogical and information technology. Integration as a requirement to unite the components of learning objects is a necessary didactic tool, which allows future mediators to create a holistic view of the object being studied, forming interdisciplinary competence. This approach makes the learning process more comfortable and lays the foundation for forming students' skills of a comprehensive vision of the problems of reality, a variety of approaches to solving them.

The use of innovative technologies in the period of online learning provides the exchange of information, knowledge, 
promotes the creation of information products, fully forming the personal potential of each graduate for future professional realization. It is important that learning takes place under the conditions of constant, active interaction of all participants in the educational process. We believe that this can be implemented in interactive learning integrated classes that involve the presentation of material in blocks of different subjects. Interdisciplinarity as a type of interdisciplinary integration involves conducting binary classes aimed at forming relationships, a holistic approach to the study of academic disciplines.

Thus, the purpose of the article is actualized: to reveal the didactic potential of the binary online lesson in the disciplines "Journalism: Internet Journalism" and "Journalism: Photojournalism" as a form of education that promotes students' professional competence - critical thinking and content verification. To achieve the goal of the study, the following tasks are outlined:

- to characterize the main theoretical provisions on the concept of interdisciplinary integration and the use of non-standard forms of classes in the period of distance learning;

- justify the need for an appropriate level of media education, development and formation of critical thinking for the media;

- with the help of online questionnaires to investigate the level of awareness of media students about the importance of critical thinking in future activities and identify the most effective forms and methods in the educational process that contribute to the formation of professional competencies of a journalist;

- to develop a number of practical exercises for critical review of multimedia content, decoding of media messages, verification of information for the implementation of interdisciplinary integration of disciplines of journalism;

- to analyze the feasibility of conducting a binary lesson using innovative technologies in the disciplines "Journalism specialty: online journalism" and "Journalism specialty: photojournalism".

The modern media industry needs the formation of journalists' multi-qualification, i.e., the ability to work with different forms of content, to understand the specifics of information platforms in convergent newsrooms (Avilés \& Carvajal, 2008, p. 237). The ability to analyze, find news, use modern tools to verify information, create quality media products, in compliance with journalistic standards and rules of journalistic ethics are necessary qualities of a mediator, included in the program competencies of the educational program " Zhurnalistyka".

In the context of digitalization of society, the transition to distance learning in the pandemic period does not cause significant difficulties. In this situation, it is important to implement such pedagogical innovations that will promote the assimilation of educational material, the implementation of independent and individual work, constructive cooperation of all participants in the educational process (Yilmaz, 2021). We believe that conducting a binary online lesson in journalism as an integrated form of learning using information and communication technologies helps motivate students to learn the material, increases the effectiveness of practical classes, helps to realize creative potential, develops communication skills, develops professional competencies.

\section{Analysis of Literature Data and Problem Statement}

During the global pandemic, when the use of traditional forms and methods is not always possible, it is important to optimize the strength and knowledge of both teachers and students to ensure the quality of education. Given the rapid development of innovative technologies, there is a need to choose forms and methods of learning that will promote learning that meets the requirements of the digital society. Interactive learning with the use of information and communication technologies, in time, is the scientific interest of Ukrainian scientists. Scientists studied innovative teaching methods using different information platforms: Sinorub \& Dragan-Ivanets (2020) (technologies of streaming on YouTube channels during the presentation of student projects), Medinska (2019) (technologies of information visualization in the educational process ), Jordan (2018) (interactive teaching methods in the system of professional training of journalists), Kushnir and Reshetukha (2021) (fact-checking technologies in the context of forming students' critical immunity), Poplavskaya and Dashchenko (2013) (cross-media technologies in broadcasting media messages). Some aspects of the use of information and communication technologies for the organization of freelance students, features of independent work with the use of cloud services reflected in the works of Aleksanyan, the creation of educational resources in the moodle atmosphere with the use of cloud technologies in their studies. Thus, online learning tools allow the transition from the subject principle of building the content of education to creating integrated training courses that combine the tools of different learning technologies and help improve the training of future professionals, the formation of his competencies (Kuzmina et al., 2020). 
Due to the pandemic, educational institutions are forced to switch to distance learning as the only possible one. Development of an effective structural and functional model of the organization of the network course, which meets the needs and realities of free trade, on time. Scientist S. Sysoyeva described the general characteristics of educational systems of the European Union and the prospects of distance learning in higher education in Ukraine (Sysoeva et al., 2020). Scientists Chen et al. (2021) identified two forms of distance learning: synchronous and asynchronous; Moore and Kearsley (2012) offered a systematic view of online learning; Supriyatno et al. (2020) specified the means of online learning that promote the development of critical thinking of students. Researchers $\mathrm{Al}$ Lily et al. (2020) conducted a comparative analysis of traditional and crisis distance education. Media ecologist Marshall McLuhan has created the first media literacy training program for the National Association of Educational Broadcasters (NAEB) in the United States, in which he presented the main ways to combat the negative effects of technology (Kuskis, 2015); Buckingham (2013) substantiated the relevance of media education as a factor in improving the quality of education and the level of youth culture. Scientist Yilmaz (2021) identified the impact of integrated learning technologies on developing professional competencies: critical and creative thinking of students. Thus, distance learning is a promising form of learning organization. Still, the problem of improving the efficiency of the educational process with the use of information technology, interdisciplinary integration remains relevant.

Methodological substantiation of the problem of integrated learning, combining theoretical and production aspects, is the result of the fact that the following scientific directions have been formed in Ukraine: methodological substantiation of integration issues (Honcharenko, Mal'ovanyy, Serhyeyev); determining the structure of integrated knowledge (Usatenko); research of systemic aspects of integration (Dzhulyk, Yavors'kyy); the problem of integrative processes in education (Bohdanova); development of ways to implement integration into the educational process (Vychorova, Horziy, Prokaza, Romanenko); integration of control elements in modular learning (Dzhulay); integration of theoretical and production aspects of education (Yakymovych); probabilistic and statistical aspects of integration (Yakylyashek); integration in higher education (Zhydets'kyy); interrelations of integration and differentiation (Morhun); psychological aspects of integration (Yatsenko); formation of knowledge system - didactic integralogy (Kozlovs'ka) (Nova Pedahohika, n.d.).

In training future professionals there is a need for an integrated approach to teaching subjects - binary classes, as a non-standard form of learning that implements interdisciplinary links. This is the creativity of teachers, which gradually grows into students' creativity and forms in the latter professional competencies, increasing motivation to learn. The method of conducting binary classes is the subject of research by foreign scholars. Thus, scientists Bekzhanova and Ryssaldi (2015) attempted to prove the effectiveness of binary lecture courses by experiment in an academic group. Stanford University professor Leavitt (2006) emphasizes team learning within or between disciplines, inspiring new research ideas and intellectual partnerships between faculty. Scientists Meeuwissen et al. (2021) tried to study the effectiveness of team learning from the standpoint of social constructivism and identified three common themes that slow down the activity of teachers of different courses. Scientists Drake and Reid (2018) focus on forming competencies of future professionals of the XXI century, proposing different models of interdisciplinary integration. Among Ukrainian researchers: Ananchenko (2020) claim that binary classes are held not for the sake of external effect, but systematization of knowledge, formation of beliefs, worldview, development of thinking; Chekhovskaya and Dus (2021) emphasize that binary classes are held to integrate academic disciplines, giving students the opportunity to apply the acquired knowledge and skills in professional activities. An urgent problem of the educational process is the search for effective professional training methods for future journalists that will help create a set of disciplines of a systemic nature that can combine new forms of teaching (Kuzmina, 2020, p. 369).

The methodology for organizing binary classes for student journalists during distance learning is insufficiently developed. Of particular importance is the problem of training highly qualified specialists who are able to integrate theoretical knowledge into practical skills, think critically, verify information, effectively solve professional problems.

\section{Research Methods}

The choice of method depends directly on the purpose of the analysis, available resources and scope of work.

The following methods were used to solve the research problems:

- general scientific: analysis (to deepen the study of the effectiveness of binary classes), synthesis (during the systematization of data obtained by analysis), comparison (to compare the quality of the information in different sources to understand the concept of "integrated class" and "binary class", their benefits and shortcomings), 
generalizations (to formulate conclusions based on the collected material);

- theoretical: analysis of scientific and documentary sources using interpretation, systematization, generalization of collected information, forecasting to justify the feasibility of integration of disciplines "Journalism: Internet Journalism" and "Journalism: Photojournalism". It is used to carry out full-fledged planning of research work, to carry out qualified and productive research;

- empirical: online questionnaires to diagnose the level of awareness of media students about the importance of critical thinking in future activities and identify the most effective forms and methods in the educational process that contribute to the formation of professional competencies of a journalist.

In order to clarify the understanding of the concepts of "critical thinking" and forms of learning that contribute to the development of this quality, an online survey was conducted among students-journalists of Ternopil National Pedagogical University named after Volodymyr Hnatyuk.

The online survey aimed to implement such tasks:

- to collect data on students' understanding of the concept of "critical thinking" and its significance in the work of a journalist;

- to find out which disciplines contribute to the formation of critical thinking;

- identify forms of learning that contribute to the development of this competence.

During the pandemic (distance learning) period, it is advisable to create a questionnaire (Google-form), which allows you to add the required number of different types of questions, edit and delete them, choose the desired theme, and so on. In addition, the questionnaire can be linked to a Google spreadsheet, which automatically stores respondents' answers, which facilitates the calculation and interpretation of results. It is also possible to export data in XLS, CSV, TXT and ODS formats.

Respondents of the survey were students of 2 nd, 3rd year (78 people) full-time and part-time students studying the courses Journalism: photojournalism (2nd year: full-time - 25 people, part-time - 14), Journalism: online journalism ( 3 courses: full-time - 27 respondents, part-time - 12). All answers in the online survey were conducted by students voluntarily (without any coercion) and in order to meet the need for true and real statements. The obtained results will help increase teachers' professional level in the use of new forms of classes for the formation of critical thinking skills in future media professionals during distance learning.

\section{Research Results}

Modern media not only inform and expand man's worldview and self-knowledge, but also have manipulative and managerial potential, influencing the formation of its attitudes, changing patterns of behavior and perception of reality. Information sources shape public opinion through their target audience. Due to a lack of necessary knowledge and skills, beginner journalists and media outlets who do not have professional education can misinform consumers and negatively affect the formation of public views. On the other hand, the growing amount of information, as well as the number of channels and sources through which information is monitored and verified, require the media to have proper media education, development and formation of critical thinking. It is important to distinguish between events and attitudes to cultivate an understanding of reality.

Disciplines of the journalistic specialty, which are declared in the educational and professional program of the first (bachelor's) level, are aimed at mastering the student a set of theoretical and practical knowledge about the basic principles and principles of journalism in various media.

The course "Journalism: Internet Journalism" belongs to the cycle of disciplines, designed to provide students with a set of theoretical knowledge and practical skills about the modern online media environment and the specifics of journalism: the definition of online media, the concept of their creation, understanding the genres and creation of media content with the help of multimedia technologies, organization of online newsrooms and conditions for their successful operation.

Among the program competencies of the discipline is the ability to generate information content, create media products, disseminate information about them, plan their work and colleagues, follow the rules and principles of safe media activities on cross-media platforms; anticipate the reaction of the audience to the information product or information campaigns, taking into account the provisions and methods of science on social problems, conflicts, hybrid wars. Modern online journalism requires from a specialist efficiency, mobility, quick adaptation to new 
technologies that are constantly changing and improving. Such conditions require constant self-development, self-education of the mediator. However, for a successful professional activity, the task of a higher education institution is the formation of basic knowledge and critical thinking - something that does not change over time.

The course "Journalism: Photojournalism" also belongs to the cycle of disciplines of professional training aims to provide students with a set of theoretical knowledge on the history of origin, development of photography and photojournalism; opportunity to master the basic knowledge of theories and practices of photojournalism in Ukraine and abroad; to acquaint with researches of innovative search and completion of luminaries of photojournalism; to understand its genre structure and practical basis; to study industry features and main trends; develop basic skills for preparing your own photos, copyright and safety rules for photojournalists, tools for image verification.

The program competencies of the discipline "Journalism: photojournalism" include the following: to conduct a problem-thematic search, to use structural schemes of information presentation; analyze photographic materials and identify genres of photojournalism; work with the camera and react quickly to events; create materials in different genres of photojournalism (choice of topic, genre, shooting point, photography, choice of photos and collection of captions); to defend their professional rights during photography, to detect fake photos, to follow the rules of professional ethics.

In order to study the level of formation of critical thinking in students of journalism 2, 3 courses, we conducted an online survey, the results of which are presented in the Figures 1-7.

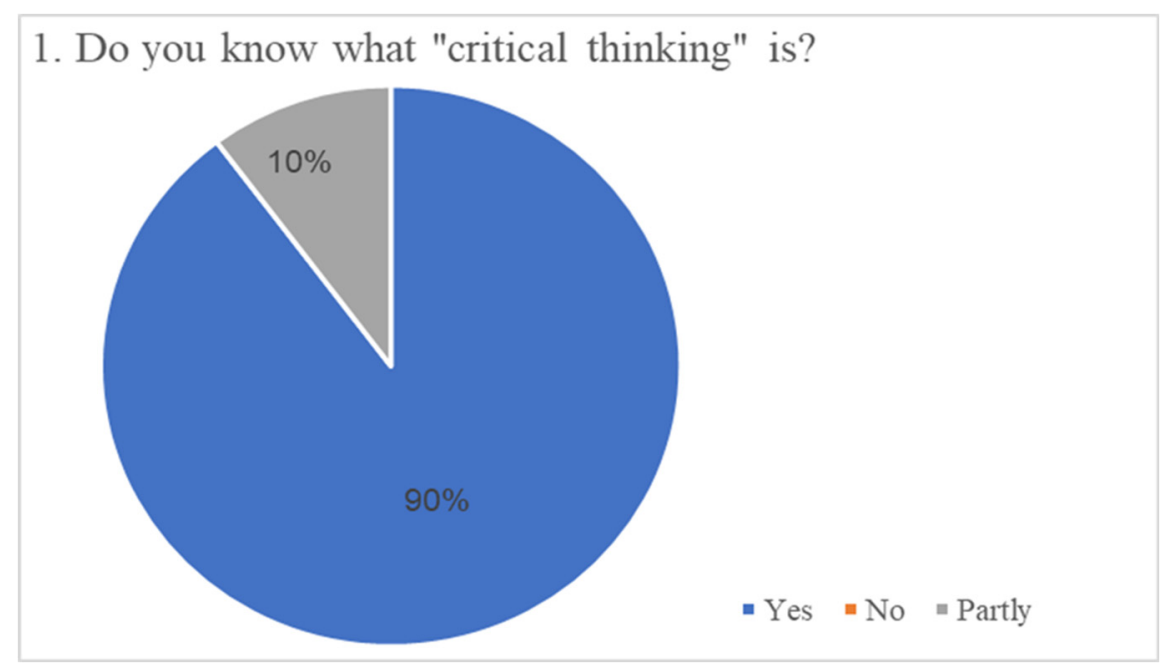

Figure 1. Understanding the Concept of "Critical Thinking"

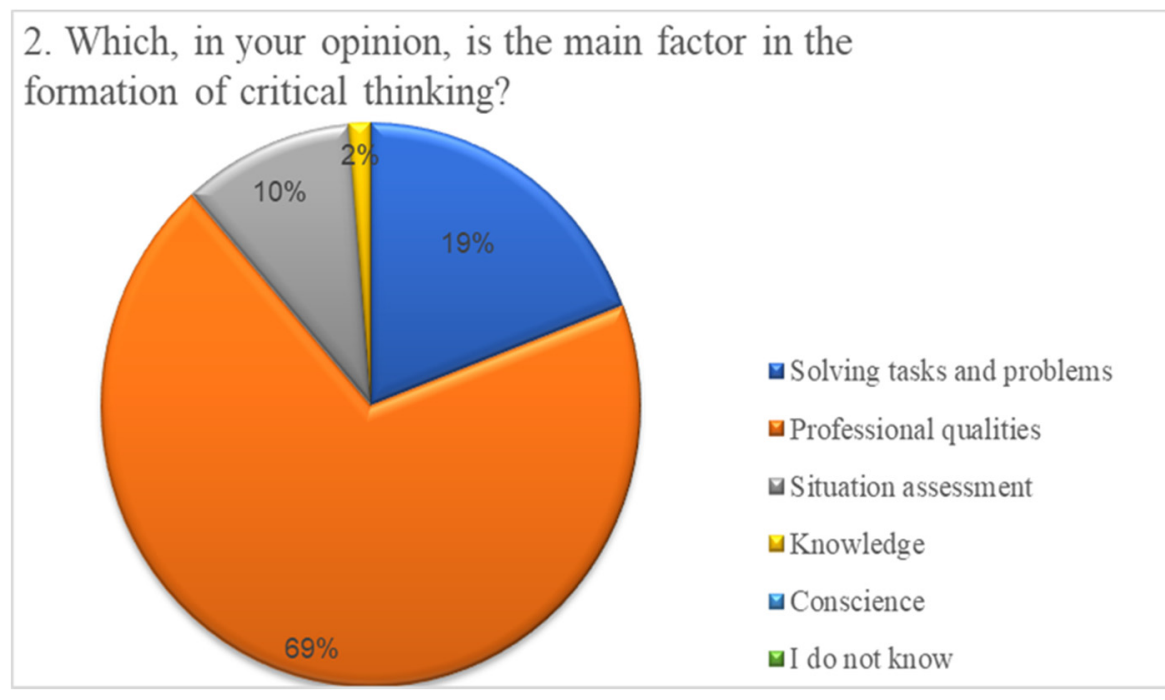

Figure 2. Factors Forming Critical Thinking 


\section{Do you have critical thinking skills?}

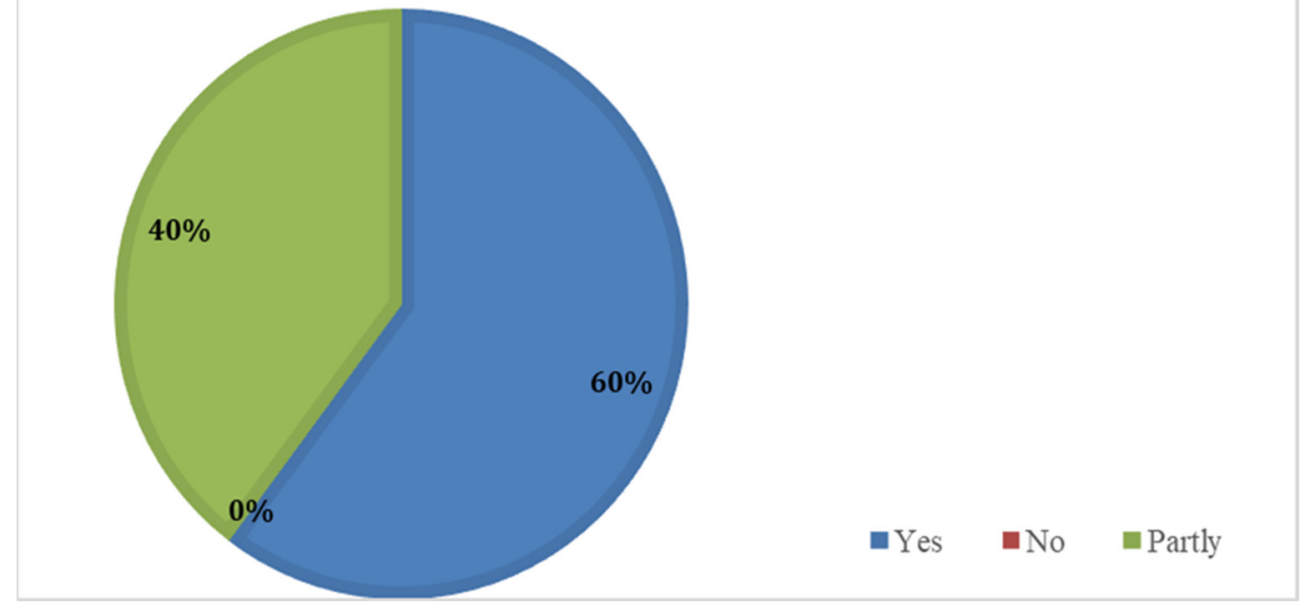

Figure 3. The Presence of Critical Thinking Skills

4. What role does critical thinking play in a journalist's work?

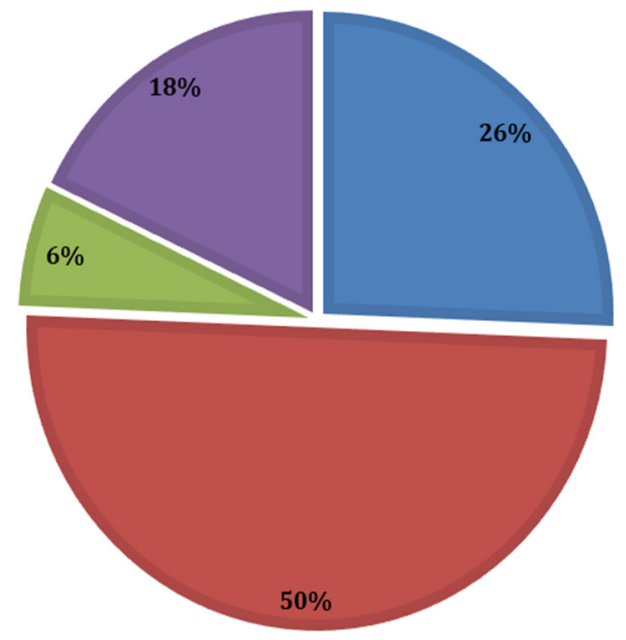

- Fakescontributes to the fight against information fakes

- Allows you to analyze to convey true information

- Possible to work with documents and primary sources (FactCheck)

- All of the above

Figure 4. The Importance of Critical Thinking in the Work of a Journalist 


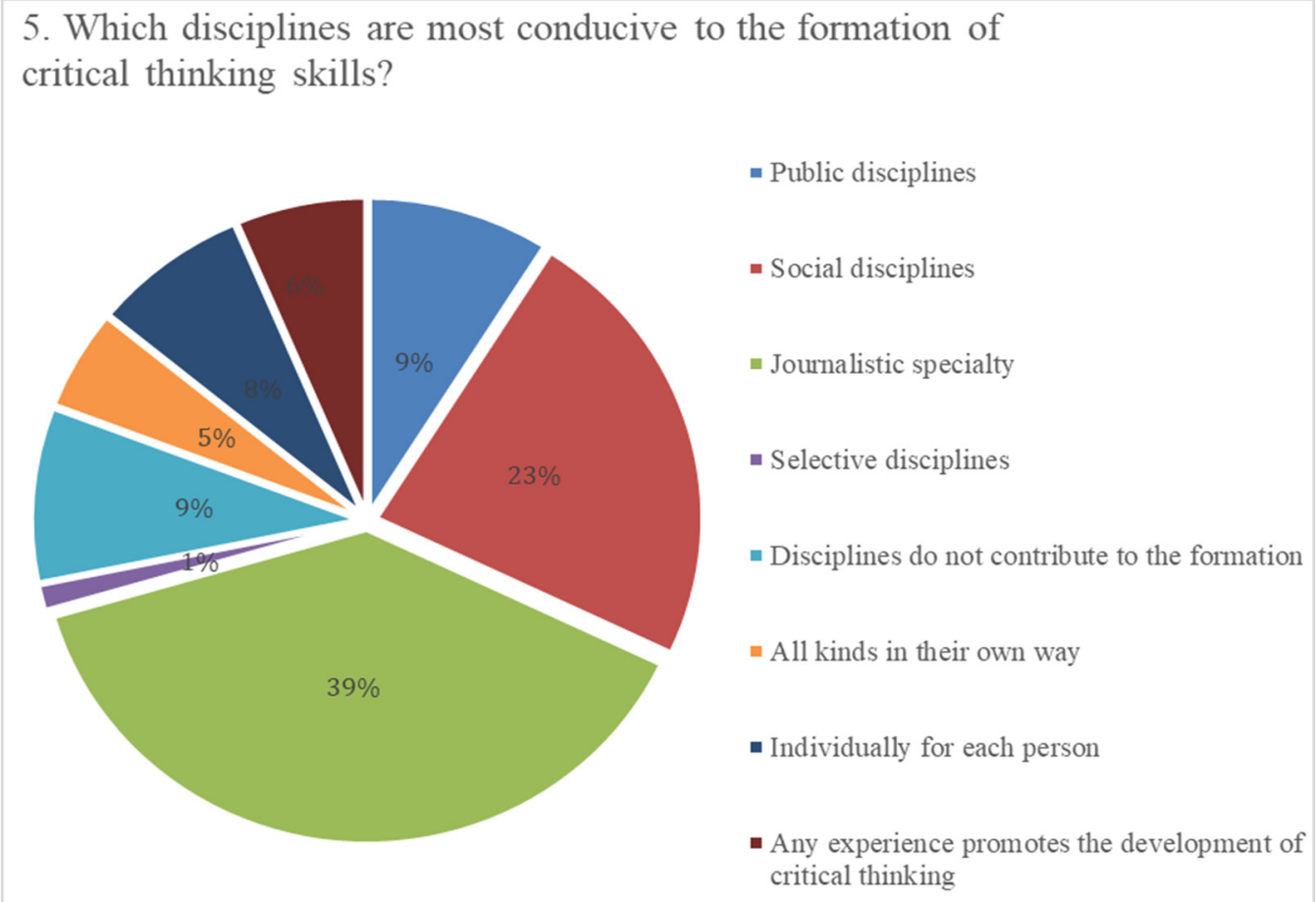

Figure 5. Educational Disciplines that Form Critical Thinking

6. How often do you watch the news you notice the critical approach of journalists to presenting information?

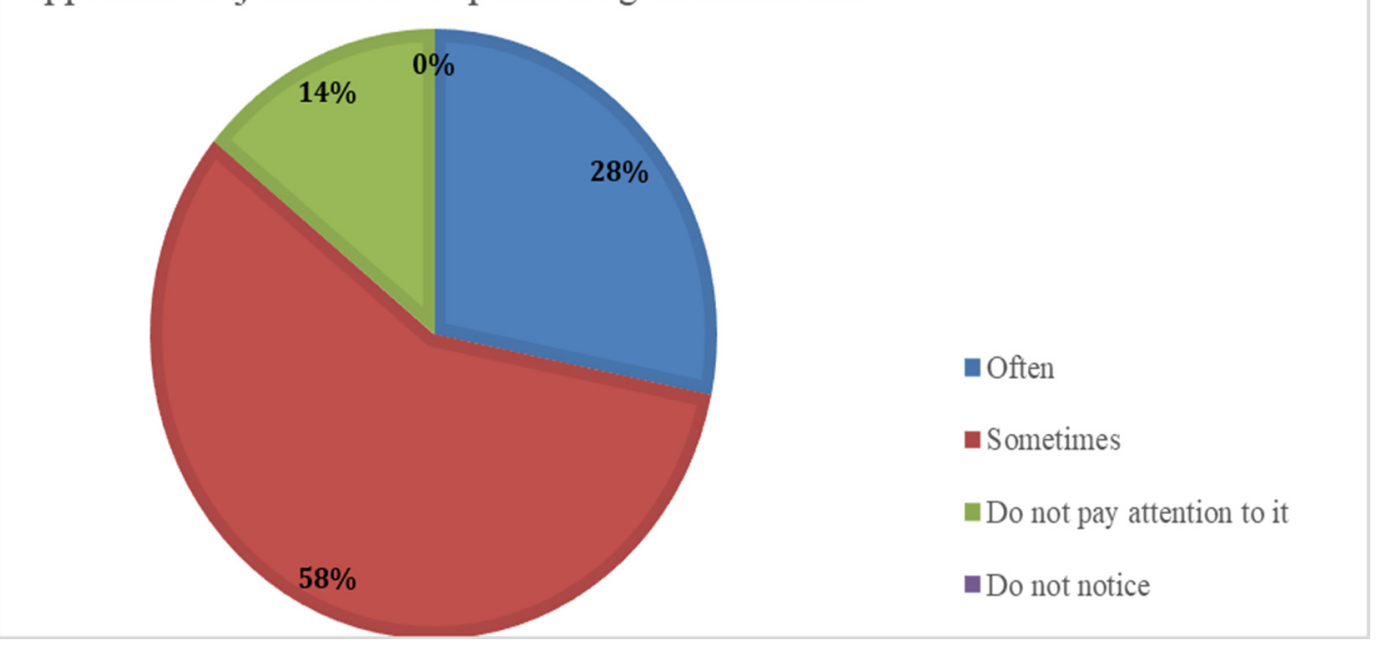

Figure 6. Manifestation of Critical Thinking in Journalists 


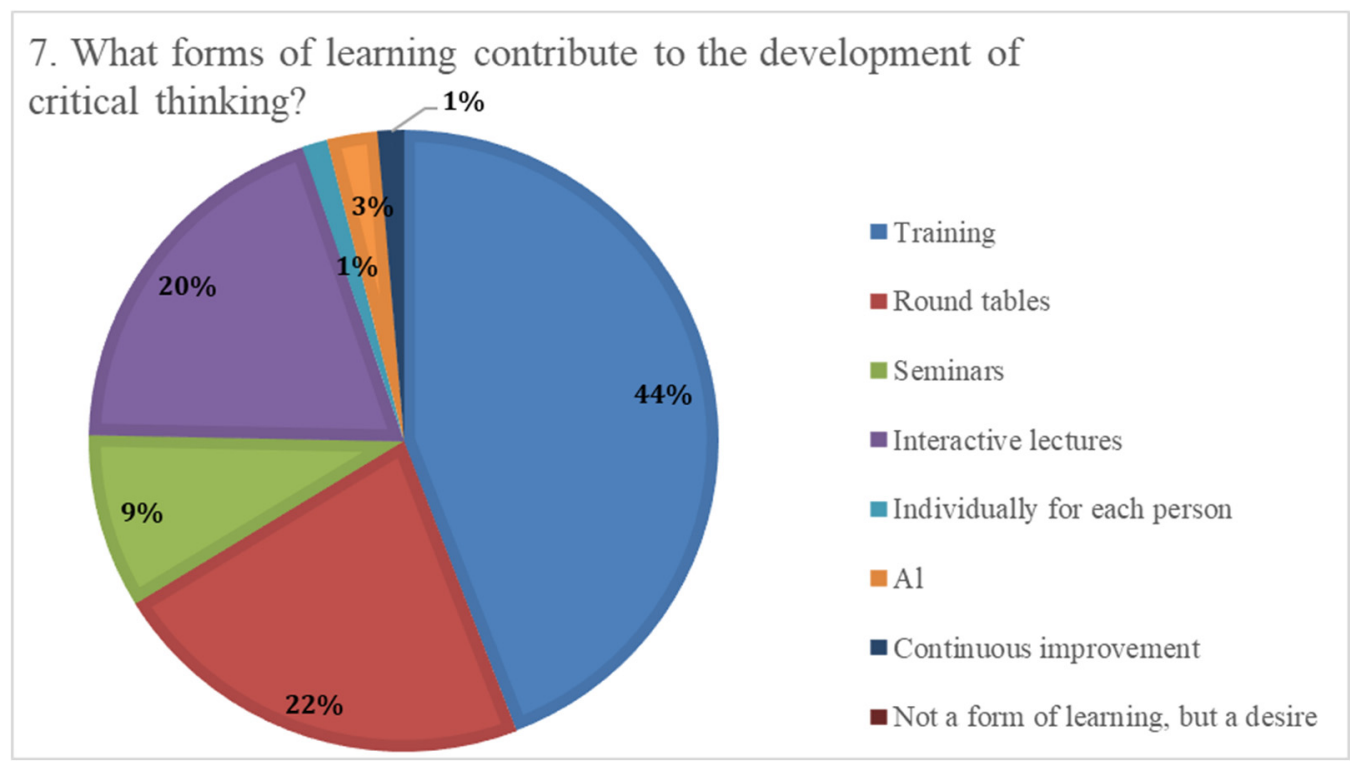

Figure 7. Forms of Learning That Promote the Development of Critical Thinking

Thus, the survey results give grounds to believe that critical thinking is a necessary quality in the work of a journalist, which is formed in the educational process through innovative forms of learning.

In the conditions of distance learning, taking into account the specifics of academic disciplines, the teacher has a task to choose the appropriate platform, types and methods of working with students, which will provide the opportunity to present material, communicate with participants using chat, chat, functions "raised hand", "breakout rooms" etc.

In order to form a responsible attitude of higher education students to online content and increase resilience to the destabilizing power of false information by using the principles and mechanisms of information verification, the idea of conducting a binary online lesson "Critical Thinking: Online Content Verification" for students journalists from the disciplines "Journalism: Internet Journalism" and "Journalism: Photojournalism" on the Zoom platform. This form of integrated learning aims at a reasoned critical review of multimedia content, the ability to decipher and use the information encoded in media messages, and applying rational methods of search, selection, systematization, and verification of information.

In the introductory part of the webinar, it is important to inform the group about the lesson's topic through a slide announcement, which lists the main issues, addresses of sites and tools that will be used to verify information during the lesson.

You need to announce the webinar rules, use of camera, microphone, headset, chat, "raised hand" function, an announcement of the seminar recording, etc. $(10 \mathrm{~min})$.

In the theoretical block (in the form of a presentation), it is necessary to acquaint students with the concept of "critical thinking", "critical thinking" and outline the mechanisms of verification of pictorial content, site (13 min.).

The practical part of the webinar consists of the following exercises:

1. Associative bush.

Objective: to understand the importance of feelings, emotions, impressions from the perception of information that arise in the process of associative thinking.

Method: work in general chat.

Execution time: 17 minutes.

Exercise description:

Step 1. The teacher asks the students to write the words and phrases that first come to mind when they hear the word "news" in the chat. Write down as many thoughts as time allows (5 minutes).

Step 2. When all the thoughts have been written down, the teacher asks the audience to connect the words and display them on an interactive whiteboard built into the Zoom platform (10 minutes). 
Discussion: Associations are not right or wrong. They are subjective. It is the process of connecting the two concepts - word and association - that is most valuable for understanding how, in creating the news, media appeal to the nonlinear thinking of the audience, produced based on feelings, emotions, attitudes ( $2 \mathrm{~min}$.).

1. Exercise "Installing the original image source"

Objective: to investigate the information about the author of the image (identify the person who uploaded the image and the person who actually created it).

Method: group work, general chat discussion.

Execution time: 15 minutes.

Exercise description:

Step 1. The teacher divides the participants into groups, forming two online halls (breakout rooms) on the Zoom platform (2 minutes).

Step 2. Students check two images of their choice from their photo library using Google Images (images.google.com), Fotoforensics (Fotoforensics.com). Teachers present in subgroups present an algorithm for verifying information (7 minutes).

Discussion: reporting the results of the photo check; finding out the number of original and borrowed photos (5 minutes).

2. $\quad$ Exercise "True or not?"

Purpose: To carry out a reasoned critical review of textual material.

Method: work in general chat.

Execution time: 20 minutes.

Exercise description:

Step 1. The teacher acquaints students with the publication "In Kyiv, new police officers saved the hipster from an overdose of the strip" on the site UAReview (3 min.).

Step 2. With the help of markers that detect fakes (the teacher shows them on the screen), the audience finds out the authenticity of the facts, checking the information with the sources mentioned in the text, verifies the image content (services Fotoforensics.com, TinEye.com), determines the authority of the UAReview site (https://uareview.com/) where the publication is hosted. The chat provides services for checking content (12 minutes).

Discussion: report on the verification results of textual material, photos and authority of the site where the journalistic material is posted ( $5 \mathrm{~min}$.).

\section{Reflection}

Purpose: to summarize the activities of each participant of the webinar.

Method: work in general chat.

Execution time: 5 minutes.

Exercise description:

Invite the group to finish the phrase "I understand today ..."

We believe that one of the most promising ways to improve the training of future professionals, equipping them with the necessary knowledge and practical skills, is the introduction of active forms and teaching methods.

One of the ways to improve the quality of learning the theoretical and practical foundations of journalism disciplines is to use interactive learning technologies (integration of journalism courses), which are most consistent with personality-oriented approach in the educational process - learning through the interaction of learners and the teacher acts only in the role of the organizer of training, the coordinator of work of groups. The use of interactive technologies requires careful training of teachers and students. They must learn to communicate successfully, use active listening skills, express personal opinions, be able to ask questions and answer them. Depending on the purpose of the lesson and the forms of organization of students' educational activities, the following interactive learning technologies are distinguished: interactive technologies of cooperative learning (work in pairs, rotating (changing) threes, carousel, work in small groups); situational modeling technologies (simulations or simulation games, simplified court hearings, public hearings, role-playing); technologies of collective-group learning 
(discussion of the problem in the general circle, microphone, unfinished sentences, brainstorming, teaching-learning, situation analysis, decision tree); technologies for processing discussion issues (PRESS method, loans-changes of position, debates, etc.).

According to a survey of 2nd and 3rd year full-time and part-time journalism students, it can be concluded that critical thinking, as a professional competence of a future journalist, is formed through journalism disciplines, in particular, "Journalism: Internet Journalism" and "Journalism: photojournalism". Conducting a binary session on the Zoom platform using various exercises allows you to delve into the text, show such mental operations as analysis, synthesis, comparison, identify doubts about media content and verify it with technical programs, which in turn will help develop critical thinking skills, infomedia literacy of the modern journalist.

\section{Discussion}

The scientific approach to understanding the concepts of "integrated lesson" and "binary lesson" deserves attention. We agree with Canadian scholars Drake and Reid (2018b) on the understanding of integrated learning as "based on a combination of knowledge from different subjects and helping to perceive the world as a whole and indivisible whole. The authors believe that teaching in the XXI century should be aimed at building competencies by creating an integrated curriculum. This approach provides in-depth learning, i.e., the transition from superficial coverage to a deep understanding of the topic, where the learner plays a leading role in the learning process (Drake \& Reid, 2018a, p.37). However, the question remains: how integrated learning completion of training, i.e., in the process of practical activities (Njuguna, 2020). In the works of scientists, the terms "integrated" or "interdisciplinary" are often used as synonyms (Drake \& Reid, 2018a, p.35). According to scientists Sdunekv, A., Waitz, T., the interdisciplinary approach in the educational process is characterized by: synthesis of content and skills, promotes meaningful research, demonstrating logical connections; application of problem-based learning (Sdunekv \& Waitz, 2017). In this version, the student becomes an important educational entity, actively communicates with the teacher, demonstrates their knowledge gained in independent work with various sources of information. An interdisciplinary, integrated approach promotes team learning.

Team learning has many pedagogical and intellectual benefits: it can help create a dynamic and interactive environment, provide teachers with useful ways to model thinking within or between disciplines and inspire new research ideas and intellectual partnerships between teachers. However, to experience the full benefits of team learning, teachers need to adjust course planning and audience management strategies to adapt the approach to collaboration.

Based on the considered scientific approaches, we believe that the binary lesson proposed in this study is one of the forms of integrated learning. The embodiment of integrated technology promotes the implementation of interdisciplinary links and the effectiveness of teamwork. The effectiveness of binary lectures in teaching in their works noted scientists Bekzhanova and Ryssaldy (2015), the feasibility of introducing gamification and augmented reality elements in binary classes (Buzko et al., 2018) and the introduction of binary classes as STEM education in the educational process studied - Buzko and Bonk (2017). We emphasize the importance of using this form of teaching in distance learning, which will promote the acquisition of theoretical and practical knowledge, the formation of professional competencies of student-journalist. The presence of two sources of information and two points of view on one scientific problem teaches students to compare, express critical remarks, tolerate different scientific concepts, and form a culture of discussion (Podoziorova \& Litvinenko, 2013). In our case, a binary lesson is a study session built on close interdisciplinary links, conducted jointly by two teachers of journalism: photo and online journalism. It aims to develop critical thinking (Ruminski \& Hanks, 2020) - a system of judgments that allows you to analyze information in such a way as to make rational decisions, to be able to distinguish lies from truth, which is extremely important in the so-called post-truth era in which we now live (Paul, 1993). Note that the binary online lesson "Critical Thinking: Verification of Online Content", which covers dynamic and relevant interdisciplinary topics, promotes the formation of integrated skills, which, in turn, is the result of effective learning and teaching (Sinorub \& Jordan, 2021).

The introduction or integration of special training courses aimed at forming future journalists' competencies in information literacy helps to increase the level of their professional training, understanding the role of mediators in the ideological education of the audience and the formation of its cultural values. The application of critical thinking development technology provides future specialists with research skills, which consist in such abilities as instant understanding, analysis, evaluation of new material; distinguish true information from fictitious; thoroughly investigate and realistically evaluate the facts; think independently, boldly, creatively; to find various ways of 
verifying and confirming any information (Morrison-Shetlar \& Marwitz, 2001).

\section{Conclusions}

Studying the scientific approaches of domestic and foreign scientists found out theoretical principles of using information and communication technologies in the integrated distance learning of students majoring in "Journalism". The study focuses on the problem of determining interdisciplinary links and their role in the process of deepening and refining the knowledge gained from the material of the disciplines of journalism.

Analyzing the results of the online questionnaire, it was found that with the help of interactive forms of learning, in particular, the binary online lesson "Critical thinking: verification of online content" in the disciplines "Journalism: online journalism" and "Journalism: photojournalism", increases critical thinking and skills of information verification are formed. These qualities are the program competencies of future journalists, a requirement of time and a trend of modern education.

As a result of the binary online lesson we managed to implement the main task - to develop a number of practical exercises and guidelines covered in the relevant sections of the interdisciplinary integration of disciplines "Journalism: Internet Journalism" and "Journalism: Photojournalism". This contributes to the formation of students' professional competence - critical thinking and verification of information, using appropriate web resources.

In the process of conducting a binary online lesson on the disciplines of journalism, applicants develop the ability to apply rational methods of search, selection, systematization, verification of text, photos and videos, use special online services that detect content manipulation, implement professional ideas; responsible attitude of future media people to the use of existing and creation of their own content, which forms their positive professional image and public authority. New learning technologies give impetus to students' self-realization, create an atmosphere of cooperation, and increase teachers' responsibility for the results of their work. The binary online lesson "Critical Thinking: Verification of Online Content" in the disciplines "Journalism: Internet Journalism" and "Journalism: Photojournalism" is the latest and most effective form of distance learning for the training of future media professionals.

At the present stage of development of the educational process, the following trends can be traced: the formation of a system of lifelong learning; creation of a single information space; synthesis of means and methods of traditional education with information and communication technologies; active introduction of new tools and methods of teaching, which are focused on the use of information and communication technologies. We see prospects for further research in the study of the level of effectiveness of integrated forms of learning, the use of innovative methods and teaching aids in the process of binary classes.

\section{References}

Al Lily, A. E., Ismail, A. F., Abunasser, F. M., \& Alqahtani, R. H. A. (2020). Distance education as a response to pandemics: Coronavirus and Arab culture. Technology in society, 63, 101317.

Ananchenko, Yu., Voronina, N., \& Skorokhodova, L. (2020). Binary class as a form of realization of interdisciplinary connections in the process of preparing students in the conditions of professional higher education: from the experience of machine-building college of Sumy State University. Physical and mathematical education, 3(25), Part 1, 19-24.

Avilés, J. A. G., \& Carvajal, M. (2008). Integrated and cross-media newsroom convergence: Two models of multimedia news production - The cases of Novotecnica and La Verdad Multimedia in Spain. Convergence, 14(2), 221-239.

Bekzhanova, Z., \& Ryssaldy, K. (2015). Efficiency of Binary Lectures in Teaching Major Linguistic Courses (Linguistics of Discourse and Cognitive Linguistics). Procedia-Social and Behavioral Sciences, 214, 430-438. http://dx.doi.org/10.1016/j.sbspro.2015.11.703

Buckingham, D. (2013). Media education: Literacy, learning and contemporary culture. New Jersey: John Wiley \& Sons.

Buzko, V., \& Bonk, A. (2017). Implementation of binary lessons as a STEM-education in the process of education in a secondary school. In: Proceedings of the 2nd International scientific and practical workshop on STEM-education - problems and prospects. KLA NAU, 19-21.

Buzko, V., Bonk, A., \& Tron, V. (2018). Implementation of gamification and elements of augmented reality during 
the binary lessons in a secondary school. Educational dimension, 51, 74-83.

Chekhovskaya, Y., \& Dus, S. (2021). The use of binary classes in the teaching of the discipline "physical education" in higher education. Scientific journal of the National Pedagogical University named after M.P. Drahomanov. Series 15. Scientific and pedagogical problems of physical culture. https://doi.org/10.31392/NPU-nc.series15.2021.5(135)

Chen, E., Kaczmarek, K., \& Ohyama, H. (2021). Student perceptions of distance learning strategies during COVID-19. Journal of dental education, 85(S1), 1190-1191. https://doi.org/10.1002/jdd.12339

Drake, S. M., \& Reid, J. L. (2018). Integrated curriculum for the twenty-first century. In: International Handbook of Holistic Education (pp. 118-128). New York: Routledge.

Drake, S. M., \& Reid, J. L. (2018a). Integrated curriculum as an effective way to teach 21 st century capabilities. Asia Pacific Journal of Educational Research, 1(1), 31-50.

Jordan, G. M. (2018). Interactive teaching methods in the system of professional training of journalists. Innovations in science and education: modern challenges: materials of scientific essays of interns (Republic of Poland, Warsaw, 2018). Warsaw-Lviv, 162-167.

Kushnir, O. V., \& U Reshetukha, T. V. (2021). Identification of fakes in the context of the formation of critical thinking of future teachers. Scientific notes of Ternopil National Pedagogical University. V. Hnatyuk. Ser. Pedagogy. Ternopil: TNPU named after V. Hnatyuk, 1, 138-145.

Kuskis, A. (2015). The media literacy movement's debt to Marshall McLuhan. Explorations in Media Ecology, 14(3-4), 305-316.

Kuzmina, M. O., Protas, O. L., Fartushok, T. V., Raievska, Y. M., \& Ivanova, I. B. (2020). Formation of students' competence of tertiary educational institutions by practical training aids. International Journal of Higher Education, 9(7), 279-288. https://doi.org/10.5430/ijhe.v9n7p279.

Leavitt, M. C. (2006). Team Teaching: Benefits and Challenges. Retrieved from https://tomprof.stanford.edu/posting/767

Medinska, O. (2019). The use of innovative pedagogical technologies in the training of future journalists. Horizons of printing, 1(7), 100-110.

Meeuwissen, S. N., Gijselaers, W. H., Wolfhagen, I. H., \& Oude Egbrink, M. G. (2021). Working beyond disciplines in teacher teams: teachers' revelations on enablers and inhibitors. Perspectives on medical education, 10(1), 33-40.

Moore, M. G., \& Kearsley, G. (2012). Distance Education: A Systems View of Online Learning. Belmont, CA: Wadsworth.

Morrison-Shetlar, A. I., \& Marwitz, M. R. (2001). Teaching Creativity: Ideas in Action. Eden Prairie, MN: Outernet Pub.

Njuguna, J. (2020). Training Factors as Predictors of Students' Self-Efficacy Beliefs for Online Journalism Practice. IAFOR Journal of Education: Technology in Education, 8(2), 141-157. https://doi.org/10.22492/ije.8.2.08

Nova Pedahohika. (n.d.). The meaning of the concept of "integration of learning". Historical aspect of the problem of integration of educational content. Retrieved from http://www.novapedahohika.com/noloms-1380-5.html

Paul, R. (1993). Critical thinking: What every person needs to survive in a rapidly changing world. Santa Rosa, CA: Foundation for Critical Thinking.

Podoziorova, A. V., \& Litvinenko, T. O. (2013). Integrated and binary classes - an effective means of forming the professional competence of future junior specialists during natural training in universities of I-II level of accreditation. Information technologies in education, science and production, 3(4), 212-218.

Poplavskaya, N. M., \& Dashchenko, N. L. (2013). Formation of cross-media competence of student journalists. State and regions. Series: Social Communications, 3-4(15-16), 113-117.

Ruminski, H., \& Hanks, W. (2020). Critical Thinking. In: Media Education Assessment Handbook, 143-164.

Sdunekv, A., \& Waitz, T. (2017). Algae: The green all-rounder - an interdisciplinary teaching unit for middle school students. Florence: Paper presented at the International Conference on the New Perspectives in Science Education. 
Sinorub, G. P., \& Jordan, G. M. (2021). Formation of critical thinking in future media professionals (on the example of the binary online lesson "Journalism: Internet Journalism" and "Journalism: Photojournalism") (pp. 167-172). Information literacy is an integral part of the educational process of higher education: a collection of articles. Kyiv: Academy of the Ukrainian Press.

Sinorub, G., \& Dragan-Ivanets, N. (2020). Webinar as an interactive online training session (on the example of the discipline "Specialization: Internet, Television"). Scientific notes of Ternopil National Pedagogical University named after Volodymyr Hnatiuk, 1, 175-181.

Slamet, S., Amrullah, A. M. K., Sutiah, S., \& Ridho, A. (2021). Differences in the experience of lecturers and students on distance learning in higher education in Indonesia: Case study in the pandemic of Covid- 19 . Systematic Reviews in Pharmacy, 12(1), 742-747.

Supriyatno, T., Susilawati, S., \& Ahdi, H. (2020). E-learning development in improving students' critical thinking ability. Cypriot Journal of Educational Sciences, 15(5), 1099-1106. https://doi.org/10.18844/cjes.v15i5.5154

Sysoeva, S. O., Batechko, N. G., \& Trygub, I. I. (2020). Quality of higher education and expert support of its provision: the experience of the European Union: guidelines for the educational module. Kyiv: Edelweiss Publishing Company LLC.

Watkins, B. R. (2005). Developing interactive e-learning activities. Performance Improvement, 44(5), 5-7.

Yilmaz, A. (2021). The effect of technology integration in education on prospective teachers' critical and creative thinking, multidimensional 21 st century skills and academic achievements. Participatory Educational Research, $8(2), 163-199$.

\section{Copyrights}

Copyright for this article is retained by the author(s), with first publication rights granted to the journal.

This is an open-access article distributed under the terms and conditions of the Creative Commons Attribution license (http://creativecommons.org/licenses/by/4.0/). 